\title{
Cholesterol Adsorption from Artificial Human Plasma with Molecular Imprinted Polymeric Nanostructures
}

\section{Moleküler Baskılanmış Polimerik Nanoyapıları ile Yapay İnsan Plazmasından Kolesterol Adsorpsiyonu}

\section{Research Article}

\section{Tülden Inanan ${ }^{1,2^{*}}$ and Nalan Tüzmen ${ }^{3}$}

'Dokuz Eylul University, The Graduate School of Natural and Applied Sciences, Izmir, Turkey.

${ }^{2}$ Aksaray University, Tech. Voc. Sch. of Higher Education, Dept. of Chem. and Chemical Processing Technology, Aksaray, Turkey.

${ }^{3}$ Dokuz Eylul University, Faculty of Science, Chemistry Division, Izmir, Turkey.

\section{A B S TR AC T}

T

his study reports cholesterol adsorption from artificial human plasma using MIP nanostructures prepared with different template:monomer ratios. The adsorption capacity of CP is $19.9 \%$ and $16.1 \%$ higher than those of $C 3 P$ and $C P 3$, respectively and adsorption capacity of CP is significantly higher than NIP nanostructures. All selectivity coefficients and relative selectivity values were higher than 1 for artificial human plasma. Under optimum conditions, considerably high cholesterol was adsorbed from hypercholesterolemic plasma (95.33\%).

\section{Key Words}

Cholesterol; molecular imprinting; plasma; nanostructures.

\section{öz}

u çalışma, farklı kalıp-monomer oranları kullanılarak hazırlanmış MIP nanoyapıları ile yapay insan plazmasından kolesterol adsorpsiyonunu sunmaktadır. CP'nin adsorpsiyon kapasitesi C3P ve CP3'e göre sırayla $\% 19,9$ ve \%16,1 daha yüksektir ve CP'nin adsorpsiyon kapasitesi NIP nanoyapılarına göre önemli derecede yüksektir. Tüm seçicilik katsayıları ve bağıl seçicilik değerleri yapay insan plazması için 1'den büyüktür. Optimum koşullarda, hiperkolesterolemik plazmadan oldukça yüksek kolesterol (\%95.33) adsorplanmıştır.

\section{Anahtar Kelimeler}

Kolesterol; moleküler baskılama; plazma; nanoyapılar.

Article History: Received: Oct 07, 2017; Revised: Oct 26, 2017; Accepted: Feb 23, 2018; Available Online: Mar 26, 2018.

DOI: $10.15671 / \mathrm{HJBC} .2018 .236$

Correspondence to: T. Inanan, Dokuz Eylul University, The Graduate School of Natural and Applied Sciences, Izmir, Turkey. 


\section{INTRODUCTION}

$\mathrm{M}$ olecular imprinted polymers (MIPs) are multi-purpose synthetic materials which are contemplated with pre-specified selectivity for a target molecule [1-4]. MIPs gain certain interest due to their selectivity to target molecules [5]. In comparison with biological counterparts such as antibodies, enzymes or biological receptors, MIPs have superior advantages: easy to prepare, good physical and chemical stability, economic, and applicability in harsh chemical media without loss of binding features [6-8].

In the preparations of MIPs, firstly functional monomers are arranged around the template and polymerized in the presence of cross linking agent $[7,9]$. Covalent [10] or noncovalent interactions [11-13] can be exploited to organize the functional monomers around the template [14]. Recognition and binding properties are influenced by the functional monomers, crosslinker used in polymerization. In addition, crosslinking degree and monomer:template ratio are critical parameters for MIP performance [15-16].

This rapidly developing technique that ensured excellent molecular recognition [17] has potential use in chromatographic separations, [18], sensors [19-21] and several extraction methods [22-23]. Extraction or determination of several molecules by MIPs were applied to environmental samples such as tap, river, well, lake, surface, waste and pond water samples; to biological samples such as urine, plasma, serum, blood and to food matrices such as milk, tomato, egg [24].

Cholesterol is one of the important biological molecule that is precursor of bile acids and steroid hormones. However, high cholesterol levels in blood induce coronary heart disease, arteriosclerosis, myocardial infarction, brain thrombosis, lipid metabolism dysfunction, hypertension, etc [25]. Thus, studies by several methods including physical, chemical, and biomedical approaches [26] had been done for cholesterol removal [27]. Physical methods are based on adsorption by hybrid material [28] supercritical fluid extraction [29], hydrophobic adsorbent [30] and molecular imprinted technique [28, 31-33].
Inthisstudy, MIPnanostructureswereprepared by surfactant free emulsion co-polymerization using different monomer:template ratios (1:1 [35]; 1:3 and 3:1) and applied for cholesterol adsorption from artificial human plasma. N-Methacryloylamido-(L)-phenylalanine methyl ester (MAPA) and 2-hydroxyethyl methacrylate (HEMA) were used as monomers and ethylene glycol dimethacrylate (EGDMA) and cholesterol were used as the cross-linker and the template, respectively. Pre-polymerization complexes were characterized by FTIR, UV and NMR spectroscopies. After polymerization process, $86 \%$ of imprinted cholesterol was removed and removed template was identified by high performance liquid chromatography (HPLC) and FTIR. Cholesterol adsorption onto nanostructures was studied from commercial human plasma by investigating the effects of solvent and dilution ratio. Finally, cholesterol adsorption was applied from hypercholesterolemic plasma.

\section{MATERIALS and METHODS}

\section{Materials}

HEMA (99\%) was supplied from Fluka. Methacyloyl chloride, EGDMA, cholesterol and human plasma were supplied from Sigma. Poly(vinyl alcohol) (PVA, high molecular weight, more than 99\%) and potassium persulphate (KPS) were purchased from Merck. All organic solvents were chromatographic- and all other chemicals were analytical-grade. Deionised water was obtained from a Millipore S.A.S 67120 Molsheim-France facility.

\section{Preparation and Characterization of Pre-Polymerization Complexes}

The synthesis of MAPA co-monomer was performed in accordance with the method of Say et al. [34]. Pre-polymerization complexes of cholesterol with MAPA were prepared with the template:monomer ratio as 1:1 [35], 1:3 and 3:1; and termed as CP, CP3 and C3P. Cholesterol solution was prepared in THF and mixed with MAPA at room temperature for $3 \mathrm{~h}$ in the dark. Preparation procedures of pre-polymerization complexes were summarized in Table 1. 
Table 1. Preparation procedures of pre-polymerization complexes.

\begin{tabular}{cccc}
\hline & CP $(1: 1)$ & CP3 (1:3) & C3P (3:1) \\
\hline CHO & $4.950 \times 10^{-5} \mathrm{~mol}$ & $4.950 \times 10^{-5} \mathrm{~mol}$ & $1.485 \times 10^{-4} \mathrm{~mol}$ \\
$\left(\mathrm{M}_{\mathrm{w}}: 386.7 \mathrm{~g} / \mathrm{mol}-30 \mathrm{mg} / \mathrm{mL}\right)$ & $638 \mu \mathrm{L}$ & $638 \mu \mathrm{L}$ & $1914 \mu \mathrm{L}$ \\
\hline $\mathrm{MAPA}$ & $4.950 \times 10^{-5} \mathrm{~mol}$ & $1.485 \times 10^{-4} \mathrm{~mol}$ & $4.950 \times 10^{-5} \mathrm{~mol}$ \\
$\left(\mathrm{M}_{\mathrm{w}}: 234 \mathrm{~g} / \mathrm{mol}-0.34 \mathrm{~g} / \mathrm{mL}\right)$ & $34 \mu \mathrm{L}$ & $102.2 \mu \mathrm{L}$ & $34 \mu \mathrm{L}$ \\
\hline
\end{tabular}

Characterization of pre-polymerization complexes was carried out with UV, NMR, and FTIR spectroscopies. Cholesterol, MAPA and pre-polymerization complexes were scanned to determine maximum wavelengths with UVspectrophotometer (Schimadzu 1601, Japan). H-NMR spectra of MAPA and pre-polymerization complexes were taken by liquid MERCURYplusAS 400 with $400 \mathrm{mHz}$ operation frequency. FTIR spectra of cholesterol, MAPA and prepolymerization complexes were recorded with FTIR spectrophotometer (Perkin Elmer spectrum 100 FT-IR spectrometer) with a universal ATR sampling accessory.

\section{Preparation and Characterization of Cholesterol Imprinted and Non-Imprinted Polymeric Nanopheres}

Synthesis of MIP and NIP nanostructures could be summarized as: pre-polymerization complexes were added to stabilizer solution, $0.2775 \mathrm{~g}$ PVA in $25 \mathrm{~mL}$ water, and suspended for $5 \mathrm{~min}$. HEMA $(600 \mu \mathrm{L})$ and EGDMA $(300 \mu \mathrm{L})$ were added as functional monomer and cross-linker, respectively. Finally, KPS (0.0198 g in $45 \mathrm{~mL}$ distillated water) was added as the initiator and polymerization mixture was sonicated and mixed to homogenate. After $\mathrm{N}_{2}$ flow for $5 \mathrm{~min}$, polymerization was initiated at $70^{\circ} \mathrm{C}$ and shacked at $65 \mathrm{rpm}$ for $24 \mathrm{~h}$ in a temperature controlled water bath shaker (GFL 1092). Non-imprinted polymeric (NIP) nanostructures were synthesized by the same method without adding cholesterol into polymerization mixture. Characterization studies such as FTIR analysis, particle size measurement, and scanning electron microscopy (SEM) analysis were performed synthesis and characterization data for MIP with the template:monomer ratio as 1:1 were given in our previous study [35].
Thermal gravimetric (TG) and derivated thermal gravimetric (DTG) curves at the thermal degradation of cholesterol imprinted and nonimprinted polymeric nanostructures were evaluated by an EXSTAR S11 7300 at a heating rate of $10^{\circ} \mathrm{C} / \mathrm{min}$.

\section{Template Removal Studies}

Various template removal solutions were studied for the determination of the most efficient one. Surfactants such as cetyl trimethylammonium bromide (CTAB), sodium dodecyl sulfate (SDS) and triton $\mathrm{X}-100(0.00001 \%),\left(\mathrm{NH}_{4}\right)_{2} \mathrm{SO}_{4}$ solution $(0.1 \mathrm{M})$ and THF were tested for template removal and performed two times at room temperature by shaking at $225 \mathrm{rpm}$ for $2 \mathrm{~h}$. Cholesterol concentrations of template removal solutions were analyzed with HPLC. Also, template removal supernatants were concentrated under $\mathrm{N}_{2}$ stream and were analyzed by FTIR spectrophotometer with a universal ATR sampling accessory (Perkin Elmer spectrum 100 FTIR spectrometer).

\section{Cholesterol Adsorption Studies from Artificial Human Plasma}

Firstly, adsorption capacities of MIP and NIP nanostructures were identified in methanol. 100 ppmcholesterol solution prepared in methanol was adsorbed onto $1 \mathrm{mg}$ MIP and NIP nanostructures for $30 \mathrm{~min}$ (saturation period for adsorption) at room temperature. Polymeric nanostructures were separated by centrifugation at $12000 \mathrm{rpm}$. Initial and final cholesterol concentrations were determined by HPLC.

Artificial human plasma was used for cholesterol adsorption and different dilution ratios were tested for the determination of matrix effect and dilutions were performed with 
$50 \mathrm{mM}$ pH 7.4 phosphate buffer and methanol to specify the most appropriate solvent. All diluted plasma solutions were used in cholesterol adsorption studies. Final solutions removed from nanostructures were filtered $(0.2 \mu \mathrm{m}$ Sartorius filter) and analyzed by HPLC. For cholesterol adsorption from hypercholesterolemic plasma, artificial human plasma was diluted with methanol at 1:5 dilution ratio. Then, it was spiked with 1000 ppm $\mathrm{CHO}$ solution (prepared in methanol) at 5:9 volume ratio. Initial cholesterol concentration of spiked artificial plasma for hypercholesterolemic plasma experiments was determined as $265 \mathrm{mg} /$ dL. All cholesterol adsorption experiments were performed in three replicates. For each set of data, standard statistical methods were used to determine the mean values and standard deviations. Confidence intervals of $95 \%$ were calculated for each set of samples in order to determine the margin of error.

\section{Selectivity Experiments}

Selectivity experiments were performed by competitive adsorption of progesterone, testosterone, estrone and estradiol that are the analogues of $\mathrm{CHO}$. Artificial human plasma was spiked with estrone, estradiol, progesterone and testosterone as all components would be at some concentration with $\mathrm{CHO}$.

Cholesterol analogues were quantified by the method of group Navakova with some modification with HPLC. HPLC analyses of estron (E1), estradiol $(E 2)$, testosterone $(T)$ and progesterone $(P)$ were perfomed with Thermo Hypersil Gold $150 \times 4.6 \mathrm{~mm}$, $5 \mu$ column and acetonitrile:methanol: $1 \%$ acetic acid (40:30:30, v/v/v) as mobile phase at $1.2 \mathrm{~mL} /$ $\min$ at $30^{\circ} \mathrm{C}$ [36]. Retention times for E1, E2, T and $P$ at $225 \mathrm{~nm}$ were 2.5, 2.7, 3.0 and $4.8 \mathrm{~min}$, respectively. For determination of selectivity, selectivity coefficient and relative selectivity were calculated by using equations below:

$K_{d}=\left(C_{i}-C_{f}\right) / C_{f} \times V / m=Q / C_{f}$

where $K_{d}$ represents the distribution coefficient $(\mathrm{mL} / \mathrm{g}) ; \mathrm{C}_{\mathrm{i}}$ and $\mathrm{C}_{\mathrm{f}}$ are initial and final concentrations of cholesterol $(\mathrm{mg} / \mathrm{L})$, respectively. $V$ is the sample volume $(\mathrm{L})$ and $\mathrm{m}$ is the nanostructure weight $(\mathrm{g})$.

$\mathrm{k}=\mathrm{K}_{\mathrm{d}}($ cholesterol $) / \mathrm{K}_{\mathrm{d}}(\mathrm{X})$

$k^{\prime}=k(M I P) / k(N I P)$

where $\mathrm{k}$ represents selectivity coefficient; $\mathrm{X}$ is the cholesterol analogue and $k$ ' is relative selectivity.

\section{RESULTS and DISCUSSION}

\section{Characterization of Pre-Polymerization Complexes}

Complexation between monomers and template molecules has been observed by changes in spectroscopic properties of the complexes. Maximum absorption wavelengths for cholesterol and MAPA were detected as $205 \mathrm{~nm}$ and $318 \mathrm{~nm}$, respectively. All pre-polymerization complexes have UV absorption peaks at $310 \mathrm{~nm}$. Shifts observed at the maximum wavelengths of prepolymerization complexes demonstrated the complexation of cholesterol with MAPA.

FTIR spectra of pre-polymerization complexes were recorded for comparison of incorporation into pre-polymerization complexes and given in Figure 1. Stretching vibrations of $\mathrm{O}-\mathrm{H}$ and $\mathrm{C}-\mathrm{O}$ of cholesterol were observed at $3530 \mathrm{~cm}^{-1}$ and 1053 $\mathrm{cm}^{-1}$, respectively. An intensive band at $1740 \mathrm{~cm}^{-1}$ and a band at $1020 \mathrm{~cm}^{-1}$ correspond to $\mathrm{C}=\mathrm{O}$ and $\mathrm{C}-\mathrm{O}$ stretching of MAPA, respectively. The peak observed at $750 \mathrm{~cm}^{-1}$ was due to aromatic character in MAPA. $\mathrm{O}-\mathrm{H}$ and $\mathrm{C}-\mathrm{H}$ stretching (3400 and $\left.2900 \mathrm{~cm}^{-1}\right)$ and $\mathrm{C}-\mathrm{H}$ bending $\left(1100 \mathrm{~cm}^{-1}\right)$ vibrations of cholesterol were seen in pre-polymerization complexes. Asymmetric $\mathrm{C}=\mathrm{O}$ stretching vibration $\left(1750 \mathrm{~cm}^{-1}\right)$ of MAPA was also seen in prepolymerization complexes. On the other hand, the intensities of $\mathrm{N}-\mathrm{H}$ stretching vibrations of MAPA (3400-3500 cm $\mathrm{cm}^{-1}$ ) and $\mathrm{O}-\mathrm{H}$ stretching vibrations of cholesterol $\left(3400 \mathrm{~cm}^{-1}\right)$ decreased in pre-polymerization complexes. These findings demonstrate the complexation of cholesterol with MAPA. $\mathrm{O}-\mathrm{H}$ and $\mathrm{C}-\mathrm{H}$ stretching and $\mathrm{C}-\mathrm{H}$ bending vibrations were sharper in $\mathrm{C} 3 \mathrm{P}$ than the others because of the higher incorporation of cholesterol into pre-polymerization complex structure. Aromatic $\mathrm{C}=\mathrm{C}$ stretching vibration, seen in both cholesterol and MAPA (sharper), were detected in 


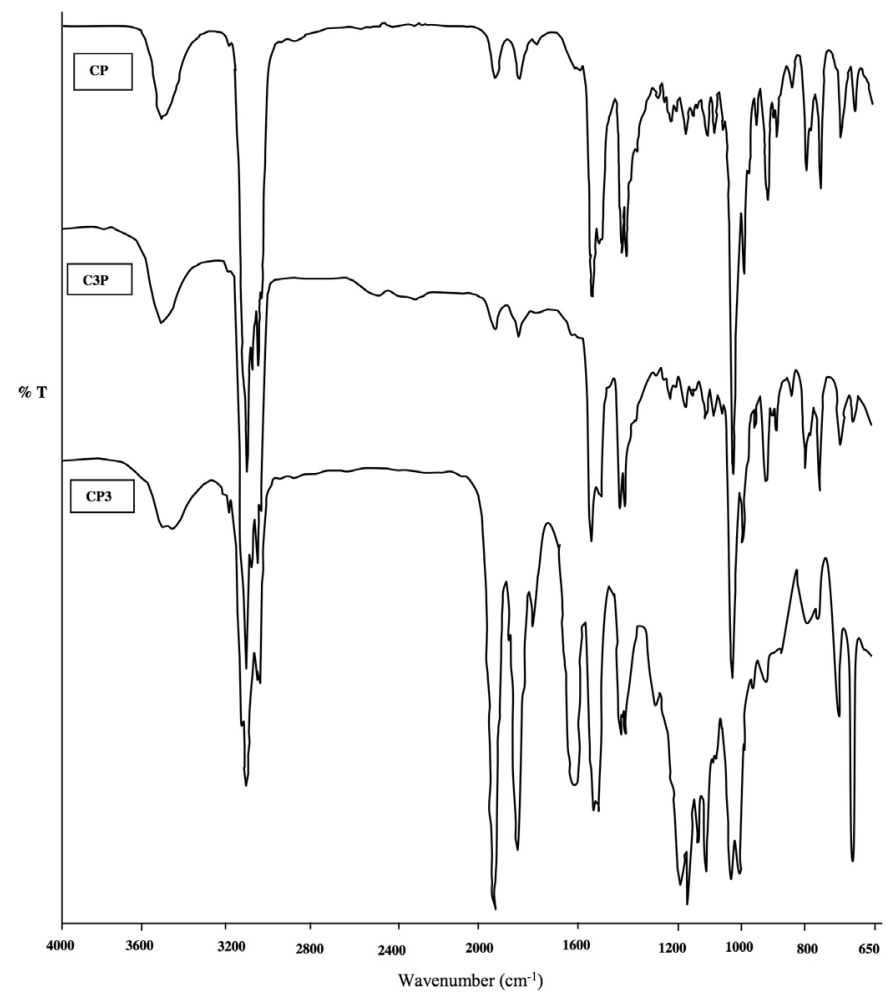

Figure 1. FTIR spectra of pre-polymerization complexes (CP, C3P, CP3).

all pre-polymerization complexes but sharper in $\mathrm{CP} 3$. Also, asymmetric $\mathrm{C}=\mathrm{O}$ stretching vibrations are sharper in $\mathrm{CP} 3$ than the others. These findings can be resulted from higher incorporation of MAPA into CP3 pre-polymerization structure.

${ }^{1} \mathrm{H}$-NMR chemical shift ranges for MAPA in $\mathrm{CDCl}_{3}$ were specified as $(\mathrm{ppm})=1.78(\mathrm{~s}, 3 \mathrm{H}, \mathrm{CH} 3)$; $5.32\left(\mathrm{~s}, \mathrm{H},=\mathrm{CH}_{2}\right), 5.57\left(\mathrm{~s}, \mathrm{H}_{1}=\mathrm{CH}_{2}\right), 5,62(\mathrm{~s}, 1 \mathrm{H}, \mathrm{CH})$; $7.17(\mathrm{~d}, 1 \mathrm{H}, \mathrm{ArH}) ; 7.23(\mathrm{~d}, 2 \mathrm{H}, 2 \mathrm{xArH}) ; 7.25(\mathrm{t}, 2 \mathrm{H}$ 2xArH), $8.29(\mathrm{~s}, 1 \mathrm{H}, \mathrm{NH})$

${ }^{1} \mathrm{H}-\mathrm{NMR}$ chemical shift ranges for $\mathrm{CP}$ prepolymerization complex in $\mathrm{CDCl}_{3}$ were specified as $(\mathrm{ppm})=0.86\left(\mathrm{~d}, 6 \mathrm{H}, 2 \times \mathrm{CH}_{3}\right) ; 0.91\left(\mathrm{~d}, 3 \mathrm{H}, \mathrm{CH}_{3}\right)$; $1.00\left(\mathrm{~s}, 3 \mathrm{H}, \mathrm{CH}_{3}\right) ; 1.07-1.22\left(\mathrm{~m}, 8 \mathrm{H}, 4 \times \mathrm{CH}_{2}\right), 1.25(\mathrm{~s}$, $\left.3 \mathrm{H}, \mathrm{CH}_{3}\right) ; 1.32-1.60(\mathrm{~m}, 17 \mathrm{H}), 1.65(\mathrm{~d}, 1 \mathrm{H}, \mathrm{CH}), 1.92(\mathrm{~s}$, $\left.3 \mathrm{H}, \mathrm{CH}_{3}\right) ; 1.95-2.08\left(\mathrm{~m}, 2 \mathrm{H}, \mathrm{CH}_{2}\right) ; 2.23-2.30(\mathrm{~m}, 2 \mathrm{H}$, $\left.\mathrm{CH}_{2}\right) ; 3.49-3.55(\mathrm{~m}, 1 \mathrm{H}, \mathrm{CH}) ; 3.71(\mathrm{t}, 1 \mathrm{H}, \mathrm{CH}) ; 3.73$ $\left(\mathrm{d}, 2 \mathrm{H}, \mathrm{CH}_{2}\right) ; 5.34(\mathrm{~m}, 1 \mathrm{H},=\mathrm{CH}) ; 7.08-7.12(\mathrm{~m}, 2 \mathrm{H}$, 2xArH); 7.23-7.31 (m, 3H, 3xArH).

Shifts (around $7 \mathrm{ppm}$ ) belong to aromatic $\mathrm{CH}$ protons of MAPA. Proton belonging to $\mathrm{C}=\mathrm{C}$ of cholesterol is seen at $5.34 \mathrm{ppm}$. Shifts at
3.71 and $3.73 \mathrm{ppm}$ belong to MAPA. $\mathrm{CH}$ proton of polar head of cholesterol is seen around $3.5 \mathrm{ppm}$. Shifts between 0-2.3 ppm belong to $\mathrm{CH}, \mathrm{CH}_{2}$ and $\mathrm{CH}_{3}$ protons of cholesterol and $\mathrm{CH}_{3}$ protons of MAPA. OH proton of cholesterol and -NH proton of MAPA are not seen in H-NMR spectrum of pre-polymerization complex. The absence of these chemical shifts makes us think that interactions between cholesterol and MAPA in pre-polymerization complex occur at these regions. Similar shifts were determined for $\mathrm{C} 3 \mathrm{P}$ and $\mathrm{CP} 3$ correlatively to the ones of $\mathrm{CP}$. The very few interactions for cholesterol binding are either $\mathrm{H}$-bonding or hydrophobic interactions [37]. Polar chemical groups, such as-OH group inmethanoldo not cause the hydrophobic effect. H-bonding interactions occur in methanol. Thus, it may be concluded that interactions at cholesterol binding to imprinted nanostructures will be $\mathrm{H}$-bonding. It was supposed that binding of several steroids to MIPs were mainly occurred through $\mathrm{H}$-bonding interactions [38]. Consequently, possible interactions between template and functional monomer may be $\mathrm{H}$-bonding. 


\section{Characterization of Cholesterol Imprinted Polymeric Nanostructures}

TG and DTG curves at the thermal degradation of cholesterol imprinted and non-imprinted polymeric nanostructures were given in Figure 2 . As seen in Figure 2, the temperature point for the maximum weight loss based on the curve of DTG was $367,408,403$ and $364^{\circ} \mathrm{C}$ for CP (green), CP3 (black), C3P (blue) and NIP (red) nanostructures, respectively. Degradation rates of polymeric nanostructures followed the order NIP $>\mathrm{CP} 3>\mathrm{C} 3 \mathrm{P}$ $>$ CP. DTG curves of all polymeric nanostructures demonstrated high thermal resistance. At about $200^{\circ} \mathrm{C}$, the polymers exhibited an obvious weight loss because of the loss of water or solvent molecules captured in the polymeric nanostructures. Therefore, this temperature was the initial decomposition temperature. In the range of $300-460^{\circ} \mathrm{C}$, polymeric nanosheres had two processes of weight loss, which was due to the production of co-polymers between HEMA and MAPA. The results showed that the prepared polymeric nanostructures have good thermal stability [33].

\section{Template Removal Studies}

Polymeric nanostructures were washed with methanol and water. Some of cholesterol was removed by ultrasonication effect in methanol washing. Several solutions were tested to remove the residual template from nanostructures.

Total cholesterol removal percentage was increased to $85.8 \%$ with THF [35], 70.3\% with $\left(\mathrm{NH}_{4}\right)_{2} \mathrm{SO}_{4}, 76.7 \%$ with Triton X-100, $74.7 \%$ with SDS, $75.7 \%$ with CTAB, and. Most efficient template removal was achieved by ultrasonic effect in $\mathrm{MeOH}$ and subsequent THF washings. Cholesterol was removed from all imprinted polymeric nanostructures and then, these nanopheres were washed with water several times to avoid from solvent remnant.

FTIR spectra of removal solution concentrated under $\mathrm{N}_{2}$ stream (a) and cholesterol standard (b) were matched and all the bands found in standard cholesterol spectrum were determined in the spectrum of removal solution. Shifts seen at some bands and also changes at the intensities of some bands might be due to chemical changes at cholesterol structure in the synthesis of prepolymerization complexes.

\section{Cholesterol Adsorption Studies from Human Plasma}

Adsorption capacities of all imprinted polymeric nanostructures were identified with 100 ppm standard cholesterol in methanol to

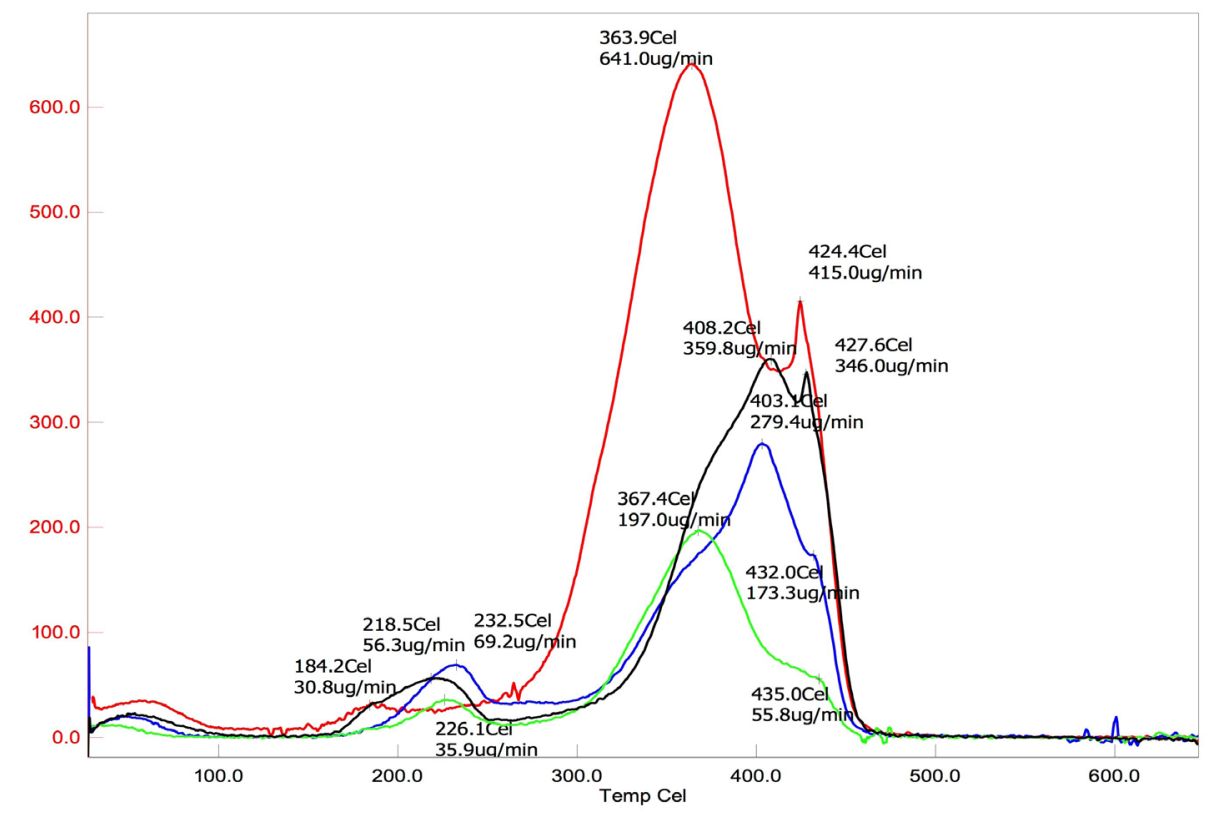

Figure 2. DTG curves of CP (green), CP3 (black), C3P (blue) and NIP (red) nanostructures. 


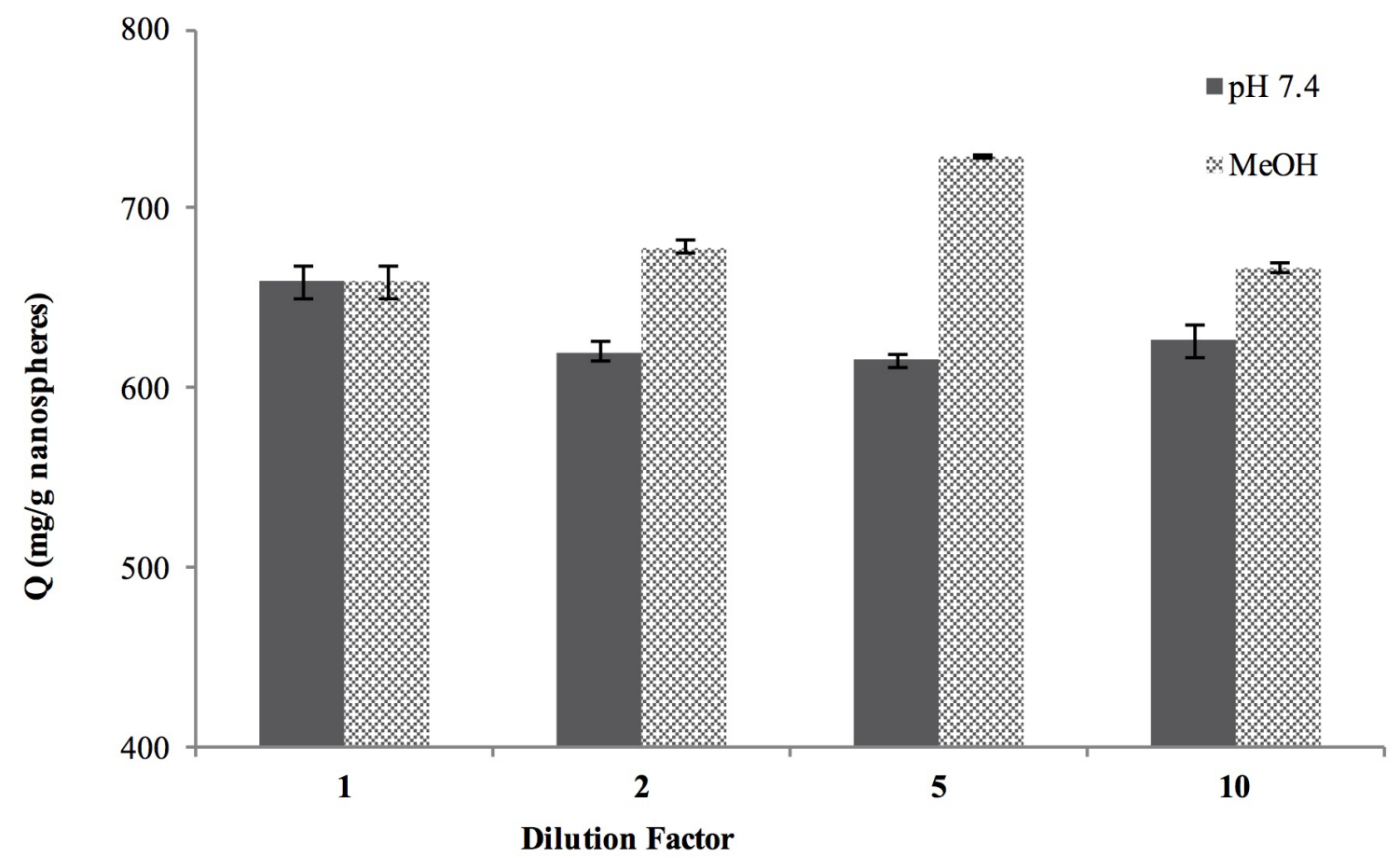

Figure 3. Adsorption capacity of CP nanostructures from artificial human plasma in different dilution solution and ratio $\left(25^{\circ} \mathrm{C}, 225 \mathrm{rpm}, 1 \mathrm{mg}\right.$ nanostructures).

determine the effect of monomer:template ratio. Cholesterol adsorption capacities of CP, C3P and CP3 nanostructures were determined as 25.9 [35], 21.6 and $22.3 \mathrm{mg} / \mathrm{g}$ nanostructures. The adsorption capacity of CP is $19.9 \%$ and $16.1 \%$ higher than those of $\mathrm{C} 3 \mathrm{P}$ and $\mathrm{CP} 3$, respectively. Then, cholesterol adsorption studies were performed with CP nanostructures from artificial human plasma with several dilutions with the 50 $\mathrm{mM}$ phosphate buffer ( $\mathrm{pH} 7.4)$ and methanol to determine the effects of dilution ratios and dilution solutions. Cholesterol adsorption capacity of CP nanostructures from artificial human plasma in different dilution solution and ratio were given in Figure 3.

As seen in Figure 3, adsorption capacity of CP nanostructures was higher with methanol dilution than the one with $\mathrm{pH} 7.4$ phosphate buffer. 1:5 dilution with methanol was the most favorable one and applied in further cholesterol adsorption studies from human plasma. In this optimum conditions, cholesterol adsorption capacities of CP, C3P and CP3 nanostructures were determined and given in Figure 4.
As seen in Figure 4, cholesterol adsorption capacities were detected as $729.4,693.9$ and 715.4 $\mathrm{mg} / \mathrm{g}$ for $\mathrm{CP}, \mathrm{C} 3 \mathrm{P}$ and $\mathrm{CP} 3$ nanostructures and $647.8 \mathrm{mg} / \mathrm{g}$ nanostructures for NIP, respectively. It can be concluded that $\mathrm{CP}$ nanostructures are more effective in cholesterol removal from human plasma. This result, compatible with the result from adsorption capacity in methanol, can be concluded that monomer:template ratio 1:1 is more convenient for cholesterol imprinting. The high adsorption capacity of NIP from artificial human plasma was a result of non-specific hydrophobic interactions.

Cholesterol removal percentage of $\mathrm{CP}$ nanostructures from hypercholesterolemic plasma was calculated as high as $95.33 \%$. This result clearly shows that these $\mathrm{CP}$ nanostructures can be used effectively for cholesterol removal from human plasma.

\section{Selectivity Experiments}

Selectivity experiments were performed by competitive adsorption of progesterone, testosterone, estrone and estradiol that are the 


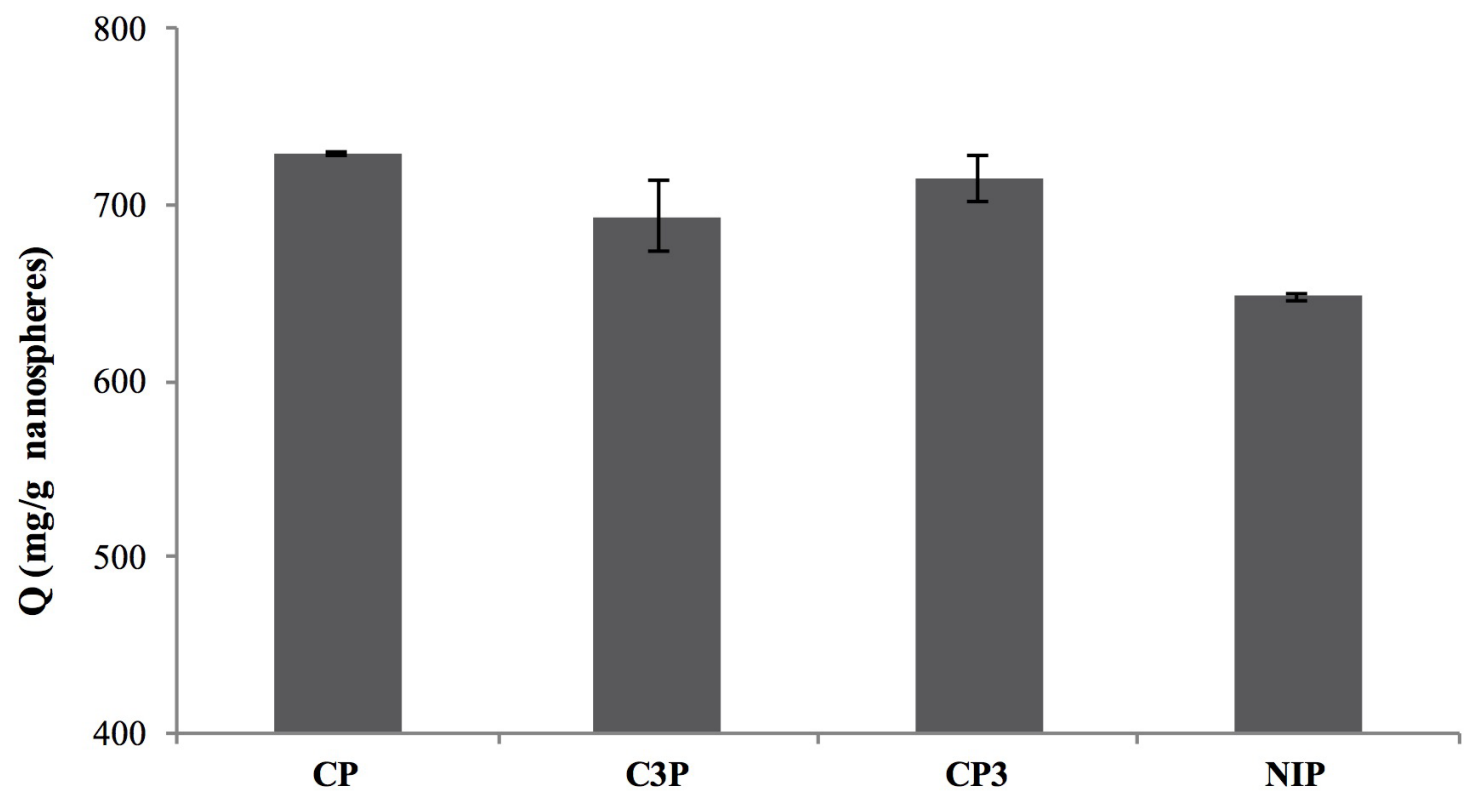

Figure 4. Cholesterol adsorption capacities of CP, C3P and CP3 nanostructures from artificial human plasma $\left(25^{\circ} \mathrm{C}, 225\right.$ rpm, 1 mg nanostructures).

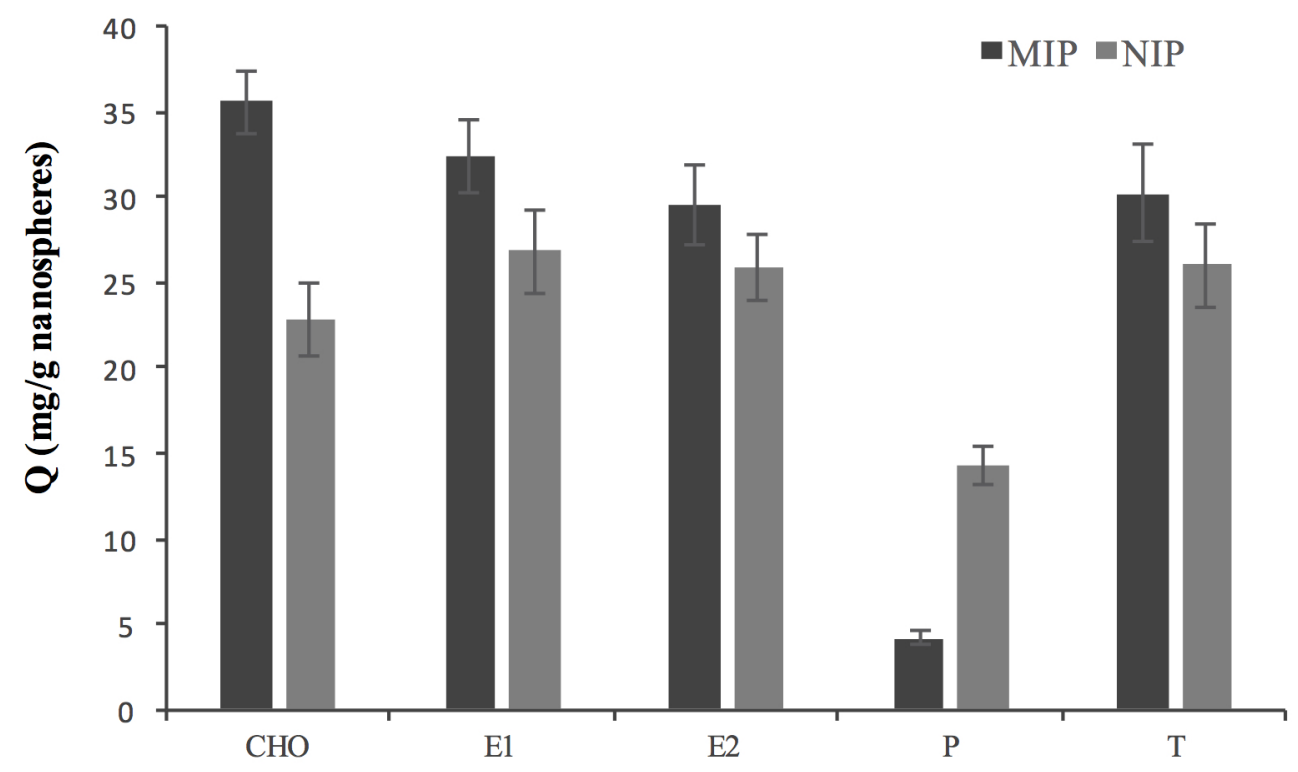

Figure 5. Amount of cholesterol and its analogues adsorbed onto MIP and NIP nanostructures in artificial human plasma $\left(25^{\circ} \mathrm{C}, 225 \mathrm{rpm}, 1 \mathrm{mg}\right.$ nanostructures).

Table 2. Selectivity coefficients and relative selectivities for artificial human plasma.

\begin{tabular}{lcc}
\hline & $k=K_{d}(C H O) / K_{d}(x)$ & $k^{\prime}=k(M I P) / k(N I P)$ \\
\hline CHO-E1 & 1.130 & 1.377 \\
\hline CHO-E2 & 1.267 & 1.480 \\
\hline CHO-T & 1.233 & 1.453 \\
\hline CHO-P & 10.781 & 6.259 \\
\hline
\end{tabular}


Table 3. Comparison of the $\mathrm{CHO}$ imprinted nanostructures with the reported adsorbents for cholesterol. removal.

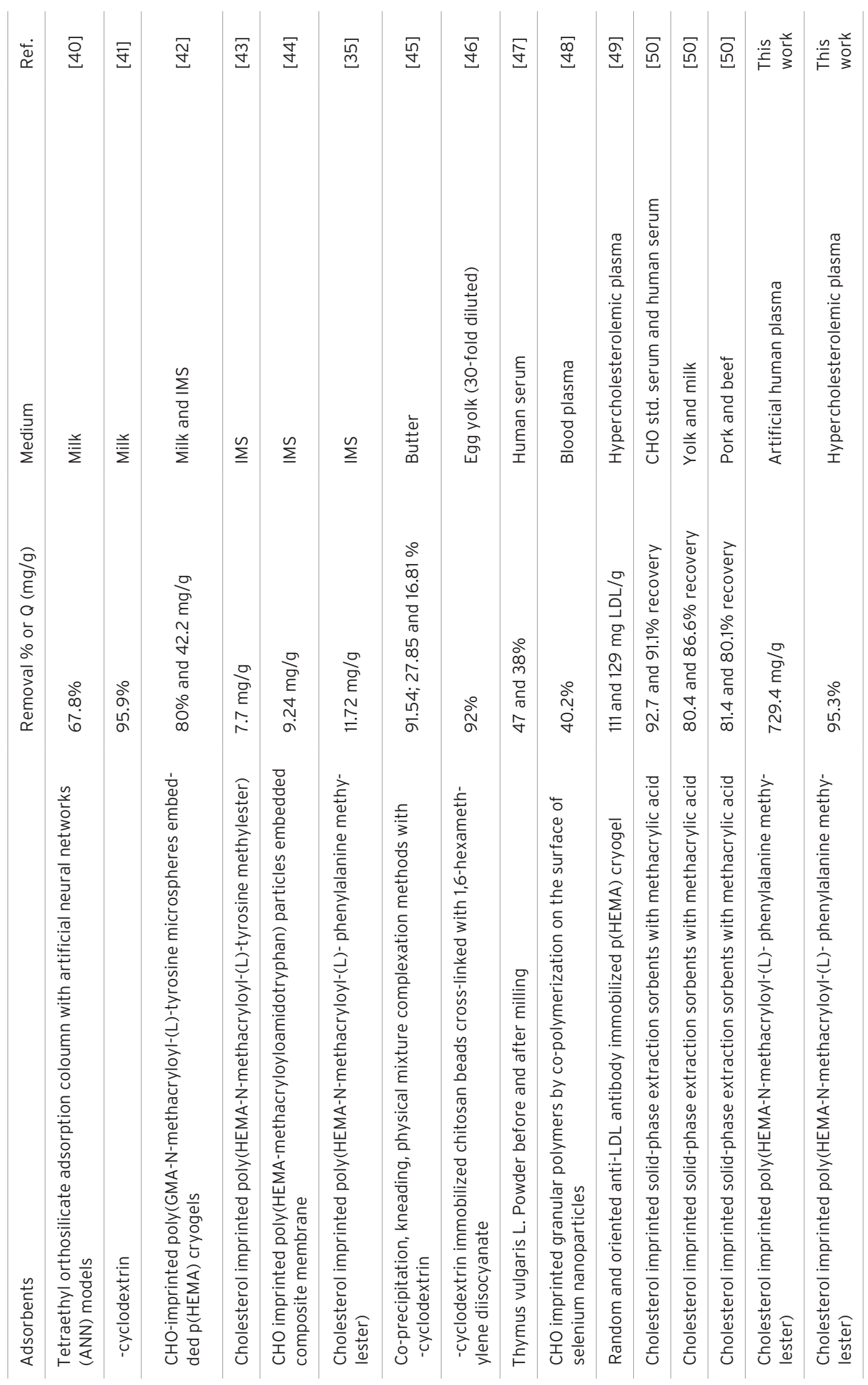


analogues of $\mathrm{CHO}$. Artificial human plasma was spiked with estrone, estradiol, progesterone and testosterone as all components would be at some concentration with $\mathrm{CHO}$.

Adsorption of cholesterol and its analogues was performed from plasma to determine the selectivity of MIP nanostructures. Amount of cholesterol and its analogues adsorbed onto MIP and NIP nanostructures were given in Figure 5.

As seen in Figure 5, amount of cholesterol adsorbed onto MIP nanostructures was higher than that of its analogues. For NIP nanostructures, amount of adsorbed estrone (E1), estradiol (E2) and testosterone ( $T$ ) was higher than that of cholesterol. Using these results, selectivity coefficients and relative selectivity values have been calculated and given in Table 2 .

All selectivity coefficients and relative selectivity values for artificial human plasma were higher than 1 . These results demonstrate that adsorption of cholesterol onto MIP nanostructures was more selective than NIP nanostructures. Moreover, MIP nanostructures adsorbed cholesterol more selectively than its analogues in artificial human plasma. The relative selectivity value for $\mathrm{CHO}-\mathrm{P}$ was calculated higher than those values for other analogues.

\section{CONCLUSION}

Monomer-template ratio is one of the parameters that are very effective on MIPs' performance $[16,28,39]$. In this study, cholesterol imprinted polymeric nanostructures were prepared by free surfactant emulsion polymerization with different monomer:template ratios. Characterization studies of pre-polymerization complexes by NMR and FTIR suggested that cholesterol may be complexed with MAPA by $\mathrm{H}$-bonding interactions. Template removal was successfully performed by $85 \%$ with methanol and THF. Thermal characterizations proved that imprinted polymeric nanostructures were resistant to high temperatures such as $400^{\circ} \mathrm{C}$. Dilution of plasma with methanol 5-times decreases the shielding effect of the plasma medium and increases the removal efficacy greatly. Moreover, notably high cholesterol removal efficacy was achieved by MIP nanostructures from hypercholesterolemic plasma. Cholesterol removal efficiency of MIP nanospheres were compared with reported adsorbents and given in Table 3. Selectivity coefficients indicate that adsorption of cholesterol onto MIP nanostructures was more selective than NIP nanostructures. Relative selectivity values show that MIP nanostructures adsorbed cholesterol more selectively than its analogues in artificial human plasma.

\section{ACKNOWLEDGEMENTS}

This study was financially supported by the Scientific Research Projects Coordination of Dokuz Eylül University, Turkey (Project number: 2012-KBFEN-107).

\section{References}

1. S.N. Hashim, R.I. Boysen, L.J. Schwarz, B. Danylec, M.T. Hearn, A comparison of covalent and noncovalent imprinting strategies for the synthesis of stigmasterol imprinted polymers, J. Chromatogr. A, 1359 (2014) 35-43.

2. E. Verheyen, J.P. Schillemans, M. Wijk, M.A. Demeniex, W.E. Hennink, C.F. Nostrum, Challenges for the effective molecular imprinting of proteins, Biomaterials, 32 (2011) 3008-3020.

3. M. Behbahani, S. Bagheri, M.M. Amini, H.S. Abandansari, H.R. Moazami, A. Bagheri, Application of a magnetic molecularly imprinted polymer for the selective extraction and trace detection of lamotrigine in urine and plasma samples, J. Sep. Sci., 37 (2014) 1610-1616.

4. C. Lu, H. Li, M. Xu, S. Wang, G. Li, W. Zhong, S.Qin, Preparation of nicotine-imprinted monolith by insitu surface imprinting onto internal hole surface of macroporous silica for selective enrichment and separation of nicotine in environmental water sample, Sep. Sci. Technol., 50 (2015) 2124-2133.

5. J. Ding, F. Zhang, X. Zhang, L. Wang, C. Wang, Q. Zhao, Y. Xu, L. Ding, N. Ren, Determination of roxithromycin from human plasma samples based on magnetic surface molecularly imprinted polymers followed by liquid chromatography-tandem mass spectrometer, J. Chromatogr. B, 1021 (2016) 221-228.

6. X. Xu, S. Liang, X. Meng, M. Zhang, Y. Chen, D. Zhao, Y. $\mathrm{Li}, \mathrm{A}$ molecularly imprinted polymer for the selective solid-phase extraction of dimethomorph from ginseng samples, J. Chromatogr. B, 988 (2015) 182-186.

7. X. Kong, R. Gao, X. He, L. Chen, Y. Zhang, Synthesis and characterization of the core-shell magnetic molecularly imprinted polymers ( $\left.\mathrm{Fe}_{3} \mathrm{O}_{4} @ M I P s\right)$ adsorbents for effective extraction and determination of sulfonamides in the poultry feed, J. Chromatogr. A, 1245 (2012) 8-16.

8. M. Andaç, I.Y. Galaev, A. Denizli, Affinity based and molecularly imprinted cryogels: Applications in biomacromolecule purification, J. Chromatogr. B, 1021 (2016) 69-80. 
9. J. Yang, Z. Wang, T. Zhou, X. Song, Q. Liu, Y. Zhang, L. $\mathrm{He}$, Determination of cyproheptadine in feeds using molecularly imprinted solid-phase extraction coupled with HPLC, J. Chromatogr. B, 990 (2015) 39-44.

10. C. Hwang, W.C. Lee, Chromatographic characteristics of cholesterol imprinted polymers prepared by covalent and non-covalent imprinting methods, J. Chromatogr. A, 962 (2002) 69-78.

11. E. Caro, N. Masque, R.M. Marce, F. Borrull, P.A.G. Cormack, D.C. Sherington, Non-covalent and semicovalent molecularly imprinted polymers for selective on-line solid-phase extraction of 4-nitrophenol from water samples, J. Chromatog. A, 963 (2002) 169-178.

12. F. Lanza, A.J. Hall, B. Sellergen, A. Bereczki, G. Horvai, S. Bayoudh, P.A.G. Cormack, D.C. Sherington, Development of semiautomated procedure for the synthesis and evaluation of molecularly imprinted polymers applied to the search for functional polymers for phenytoin and nifedipine, Anal. Chim. Acta, 435 (2001) 91-106.

13. A. Ersöz, A. Denizli, İ. Şener, A. Atılır, S. Diltemiz, R. Say, Removal of phenolic compounds with nitrophenolimprinted polymer based on $p-p$ and hydrogenbonding interactions, Sep. Purif. Technol., 38 (2004) 173-179.

14. R. Say, A. Ersöz, i. Şener, A. Atılır, S. Diltemiz, A. Denizli, Comparison of adsorption and selectivity characteristics for 4 nitrophenol imprinted polymers prepared via bulk and suspension polymerization, Sep. Sci. Technol., 39 (2004) 3471-3484.

15. E. Yılmaz, K. Mosbach, K. Haupt, Influence of functional and cross-linking monomers and the amount of template on the performance of molecularly imprinted polymers in binding assays, Anal. Commun., 36 (1999) 167-170.

16. C.H. Hu, T.C. Chou, Albumin molecularly imprinted polymer with high template affinity-prepared by systematic optimization in mixed organic/aqueous media, Microchem. J., 91 (2009) 53-58.

17. X. Sun, J. Wang, Y. Li, J. Yang, J. Jin, S.M. Shah, J. Chen, Novel dummy molecularly imprinted polymers for matrix solid-phase dispersion extraction of eight fluoroquinolones from fish samples, J. Chromatog. A, 1359 (2014) 1-7.

18. S. Aşir, D. Sari, A. Derazshamshir, F. Yılmaz, K. Şarkaya, A. Denizli, Dopamine imprinted monolithic column for capillary electrochromatography, Electrophoresis, 0 (2017) 1-10.

19. A.G. Sarıkaya, B. Osman, T. Çam, A. Denizli, Molecularly imprinted surface plasmon resonance (SPR) sensor for uric acid determination, Sens. Actuators B Chem., 251 (2017) 763-772.

20. G. Sener, E. Ozgur, E. Yılmaz, L. Uzun, R. Say, A. Denizli, Quartz crystal microbalance based nanosensor for lysozyme detection with lysozyme imprinted nanoparticles. Biosens. Bioelectron., 26 (2010) 815 821.

21. Y. Saylan, S. Akgönüllü, D. Çimen, A. Derazshamshir, N. Bereli, F. Yılmaz, A. Denizli, Development of surface plasmon resonance sensors based on molecularly imprinted nanofilms for sensitive and selective detection of pesticides, Sens. Actuators B Chem., 241 (2017) 446-454.

22. L.I. Andersson, Molecular imprinting for drug bioanalysis A review on the application of imprinted polymers to solid-phase extraction and binding assay, J. Chromatogr. B, 739 (2000)163-173.
23. E. Turiel, A. Martin-Esteban, Molecularly imprinted polymers for sample preparation: a review, Anal. Chim. Acta, 66 (2010) 887-899.

24. L. Chen, S. Xu, X. Li, Recent advances in molecular imprinting technology: current status, challenges and highlighted applications, Chem. Soc. Rev., 40 (2011) 2922-2942.

25. A. Aghaei, M.R.M. Hosseini, M. Najafi, A novel capacitive biosensor for cholesterol assay that uses an electropolymerized molecularly imprinted polymer, Electrochimica Acta, 55 (2010) 1503-1508.

26. A. Sinha, S. Basiruddin, A. Chakraborty, N.R. Jana, Cyclodextrin functionalized magnetic mesoporous silica colloid for cholesterol separation, ACS Appl. Mater. Interfac., 7 (2015) 1340-1347.

27. Y. Su, Y. Tian, R. Yan, C. Wang, F. Niu, Y. Yang, Study on a novel process for the separation of phospholipids, triacylglycerol and cholesterol from egg yolk, J. Food Sci. Technol., 52 (2015) 4586-4592.

28. D.N. Clausen, I.M.R. Pires, C.R.T. Tarley, Improved selective cholesterol adsorption by molecularly imprinted poly(methacrylic acid)/silica (PMAA-SiO ${ }_{2}$ ) hybrid material synthesized with different molar ratios, Mat. Sci. Eng. C, 44 (2014) 99-108.

29. M.M. Jimenez-Carmona, M.D.L. de Castro, Reverse micelle formation for acceleration of the supercritical fluid extraction of cholesterol from food samples, Anal. Chem., 70 (1998) 2100-2103.

30. E.E.G. Rojas, J.S.D. Coimbra, L.A. Minim, Adsorption of egg yolk plasma cholesterol using a hydrophobic adsorbent, Eur. Food Res. Technol., 223 (2006) 705709.

31. A. Zengin, E. Yildirim, U. Tamer, T. Caykara, Molecularly imprinted superparamagnetic iron oxide nanoparticles for rapid enrichment and separation of cholesterol, Analyst, 138 (2013) 7238-7245.

32. Y. Tong, H. Guan, S. Wang, J. Xu, J. He, Syntheses of chitin-based imprinting polymers and their binding properties for cholesterol, Carbohyd. Res., 346 (2011) 495-500.

33. R. Gupta, A. Kumar, Synthesis and characterization of sol-gel-derived molecular imprinted polymeric materials for cholesterol recognition, J. Sol-Gel Sci. Technol., 58 (2011) 182-194.

34. R. Say, S. Emir, B. Garipcan, S. Patir, A. Denizli, Novel methacryloylamidophenylalanine functionalized porous chelating beads for adsorption of heavy metal ions, Adv. Polym. Tech., 22 (2003) 355-364.

35. T. Inanan, N. Tuzmen, S. Akgöl, A. Denizli, Selective cholesterol adsorption by molecular imprinted polymeric nanospheres and application to GIMS, Int. J. Biol. Macromolec., 92 (2016) 451-460.

36. L. Navakova, P. Solich, L. Matysova, J. Sicha, HPLC determination of estradiol, its degradation product, and preservatives in new topical formulation estrogel HBF, Anal. Bioanal. Chem., 379 (2004) 781-787.

37. M.A. Gore, R.N. Karmalkar, M.G. Kulkarni, Enhanced capacities and selectivities for cholesterol in aqueous media by molecular imprinting: role of novel crosslinkers, J. Chromatog. A, 804 (2004) 211-221.

38. X. Li, M. Li, J. Li, F. Lei, X. Su, X. Liu, P. Li, X. Tan, Synthesis and characterization of molecularly imprinted polymers with modified rosin as a cross linker and selective SPE-HPLC detection of basic orange II in foods, Anal. Met., 6 (2014) 6397-6406. 
39. H.S. Andersson, J.G. Karlsson, S.A. Piletsky, A.C. Koch-Schmidt, K. Mosbach, I.A. Nicholls, Study of the nature of recognition in molecularly imprinted polymers, influence of monomer-template ratio and sample load on retention and selectivity, J. Chromatogr. A, 848 (1999) 39-49.

40. G.R. Oliveira, A.V. Santos, A.S. Lima, C.M.F. Soares, M.S. Leite, Neural modelling in adsorption column of cholesterol-removal efficiency from milk, LWT- Food Science and Technol., 64 (2015) 632-638.

41. D.K. Lee, J. Ahn, H.S. Kwak, Cholesterol removal from homogenized milk with $\beta$-cyclodextrin, J Dairy Sci. 82 (1999) 2327-2330.

42. K. Çaktü, G. Baydemir, B. Ergün, H. Yavuz, Cholesterol removal from various samples by cholesterol imprinted monosize microsphere-embedded cryogels Artif. Cells Nanomed. Biotechnol., 42 (2014) 365-375.

43. H. Yavuz, V. Karakoç, D. Türkmen, R. Say, A. Denizli, Synthesis of cholesterol imprinted polymeric particles, Int. J. Biol. Macromol., 41 (2007) 8-15.

44. M. Odabaşı, L. Uzun, G. Baydemir, N.H. Aksoy, Ö. Acet, D. Erdönmez, Cholesterol imprinted composite membranes for selective cholesterolrecognition from intestinal mimicking solution, Colloids Surf. B Biointer., 163 (2018) 266-274.

45. H.M.A.M. Dias, F. Berbicz, F. Pedrochi, M.L. Baesso, G. Matioli, Butter cholesterol removal using different complexation methods with beta-cyclodextrin, and the contribution of photoacoustic spectroscopy to the evaluation of the complex, Food Res. Int., 43 (2010) 1104-1110.
46. S.H. Chiu, T.W. Chung, R. Giridhar, W.T. Wu, Immobilization of b-cyclodextrin in chitosan beads for separation of cholesterol from egg yolk, Food Res. Int., 37 (2004) 217-223.

47. E. Salehi, S. Afshar, M.Z. Mehrizi, A. Chehrei, M. Asadi, Direct reduction of blood serum cholesterol using Thymus vulgaris L.: Preliminary biosorption study, Process Bichem., accepted manuscript

48. I. Polyakova, L. Borovikova, A. Osipenko, E. Vlasova, B. Volchek, O. Pisarev, Surface molecularly imprinted organic-inorganic polymers having affinity sites for cholesterol, React. Funct. Polym., 109 (2016) 88-98.

49. N. Bereli, G. Şener, H. Yavuz, A. Denizli. Oriented immobilized anti-LDL antibody carrying poly(hydroxyethyl methacrylate) cryogel for cholesterol removal from human plasma, Mater. Sci. Eng. C, 31 (2011) 1078-1083.

50. Yun S., J.H. Zhang, D.Shi, M. Jiang, Y.X. Zhu, S.R. Mei, Y.K. Zhou, K. Dai, B. Lu, Selective solid-phase extraction of cholesterol using molecularly imprinted polymers and its application in different biological samples, J. Pharm. Biomed. Anal., 42 (2006) 549555. 